\title{
Interactive Effects of Disturbance, Productivity, and Consumer Diversity on the Structure of Prey Communities
}

\author{
Christopher F. Steiner \\ Department of Biological Sciences, Wayne State University, 5047 Gullen Mall, Detroit, MI 48202, USA \\ Correspondence should be addressed to Christopher F. Steiner; csteiner@wayne.edu
}

Received 17 December 2012; Accepted 8 January 2013

Academic Editors: M. Bishop, M. A. Molina-Montenegro, J. L. Nielsen, and S. Sabater

Copyright ( 2013 Christopher F. Steiner. This is an open access article distributed under the Creative Commons Attribution License, which permits unrestricted use, distribution, and reproduction in any medium, provided the original work is properly cited.

\begin{abstract}
Experiments show that consumer diversity can have important effects on the control of prey diversity and abundance. However, theory also indicates that the strength of consumer effects on such properties will vary depending on system productivity and disturbance regime. Using a laboratory-based system composed of ciliate consumers and bacterial prey, I explored the interactive effects of productivity, disturbance, and consumer diversity on prey diversity and trophic-level abundance. Consumer diversity had productivity-dependent effects on bacterial prey that were consistent with theoretical expectations. At low productivity, increasing consumer diversity reduced prey abundance while at high productivity no effects were detected due to compensatory responses among bacteria. In contrast, consumer diversity had weak effects on prey diversity at low productivity but significantly depressed prey diversity at high productivity. Disturbance on consumers enhanced prey diversity but did not alter consumer diversity effects on prey. These results indicate that consumer diversity may play an important role in the regulation of prey communities, but the strength of this effect varies with system productivity.
\end{abstract}

\section{Introduction}

The relative importance of top-down (consumer) versus bottom-up (resource) effects on prey communities has fueled intense debate and spawned a large body of ecological research [1-5]. The strength of consumer control on trophiclevel abundance and the composition of prey has been shown to vary greatly among studies and study systems [5-8]. Such context dependency has prompted investigations into the mechanisms that may mediate top-down effects on the structure of prey assemblages, including the effects of prey defense, stage-structured dynamics, consumer diet breadth, and the form of consumer functional responses [1-3, 9-13]. A parallel body of research has focused on the effects of species loss on ecosystem functioning and biomass yield. Although initially focused on plant species diversity and its effects on primary production and nutrient uptake, several studies have shown that the number of consumer species present within a trophic level can have important impacts on secondary production and the capacity of consumers to control total abundance and diversity of prey assemblages [14-20].

Increasing diversity within a consumer trophic level can theoretically increase total consumer abundance either through niche complementarity among consumers (e.g., via resource partitioning) or through sampling effects (i.e., increased probability of inclusion of dominant consumer species with increasing diversity) $[18,20,21]$. Positive impacts of diversity on the consumer trophic level may be accompanied by simultaneous negative impacts on the prey trophic level; both total prey abundance and diversity may decline with increasing consumer diversity $[15,18]$. Declines in total prey abundance with increasing consumer diversity arise from increasing prey-use efficiency-a result of complementarity and/or sampling effects on the consumer trophic level $[16-18,20]$. Conversely, declines in prey diversity can be produced by the strengthening of apparent competition effects with increasing consumer diversity [18]. Thus, the impact of species loss on consumer trophic levels may have 
important implications for the diversity of prey assemblages and the partitioning of biomass between consumers and their prey.

Although studies have shown that consumer diversity can strengthen consumer effects on prey assemblages [14, $15,17-20,22]$, few have explicitly explored how environmental context, such as variation in system productivity and disturbance, may mediate such effects. Theory and experiments have shown that the combined impact of predation and enhanced productivity can permit the invasion and dominance of predator-resistant prey, weakening consumer control of total prey abundance [9-11, 23-26]. This occurs when prey species exhibit tradeoffs in competitive ability for shared resources and resistance to predation. At low productivity, only highly competitive, edible prey can persist with predators. Increasing productivity strengthens apparent competition among prey (mediated via the top consumer), simultaneously suppressing highly edible prey and allowing less competitive but more predator-resistant prey to invade and dominate $[9-11,24]$. The strengthening of apparent competition with increasing productivity may also be accompanied by an overall decline in prey diversity as predator-resistant species increase in dominance, excluding less resistant species [9]. Consequently, consumer control of total prey biomass declines with increasing productivity while negative effects on prey diversity increase [9]. The aforementioned models have only considered systems composed of a single predator. However, it is plausible that such effects may interact with predicted effects of consumer diversity as outlined in [18]. For instance, reduction of prey abundance with increasing consumer diversity may be more pronounced at low levels of productivity where invasion and dominance by inedible prey is less likely. Furthermore, predicted declines in prey diversity with increasing consumer diversity may be stronger at high levels of productivity due to enhanced apparent competition.

Disturbance in the form of periodic mortality can permit persistence and enhance the relative abundance of consumer species that would otherwise be excluded from communities via interspecific resource competition [2731]. Consequently, enhanced consumer richness and evenness in polyculture may, in turn, increase expression of niche complementarity among consumers and facilitate the emergence of consumer diversity effects on total consumer abundance $[32,33]$. However, disturbance focused on consumer trophic levels can concomitantly weaken top-down control and apparent competition effects on prey, enhancing prey abundance and diversity [28, 29]. Thus, consumer diversity effects on prey trophic levels, as outlined above, may be more strongly expressed under weaker disturbance regimes.

Prior studies have examined the interaction of disturbance and consumer diversity on ecosystem functioning [32, 33], but few have examined how productivity and disturbance may comediate consumer diversity effects on prey assemblages [19]. Here I report on an experiment in which I used an aquatic microbial system composed of four species of protist consumers feeding on a diverse assemblage of bacteria to explore the interactive effects of consumer diversity, productivity, and disturbance on prey diversity and trophiclevel abundance of prey and consumers. A prior analysis of this experiment focused on consumer dynamics and the effects of productivity and disturbance on bacterial diversity and the strength and outcome of competition among protists [29]. Here I focus on consumer diversity effects (contrasts between mean monoculture and polyculture treatments) on bacteria and consumer production and its interaction with productivity and disturbance. I show that productivity mediates the expression of consumer diversity effects on prey abundance and diversity, in accordance with theory. While disturbance can alter the strength of top-down effects, it exerts a much weaker interactive effect with consumer diversity.

\section{Methods}

Microcosms consisted of $200 \mathrm{~mL}$, loosely capped Pyrex bottles. All experiments were conducted within a single incubator at $22^{\circ} \mathrm{C}$ and under 24 hour dark conditions. Experimental communities were composed of a diverse bacterial assemblage and bacterivorous protists as the consumer trophic level. I employed two levels of consumer diversity: polycultures (containing all four species of bacterivore together) and monocultures (each species of bacterivore alone). Diversity manipulations were crossed with two levels of disturbance in the form of density-independent mortality events (low and high) and two levels of productivity (low and high) in a $2 \times 2 \times 2$ factorial design. Each treatment combination was replicated four times, where each shelf within the incubator contained one replicate of each treatment and acted as a block.

Bacterivores consisted of four species of ciliated protists all maintained in laboratory cultures: Paramecium aurelia, Paramecium caudatum, Loxocephalus sp., and Colpoda inflata (hereafter referred to by genus). The experimental medium consisted of distilled water and Protist Pellet (Carolina Biological Supply, Burlington, NC) as a carbon and nutrient source for the bacteria. Productivity was manipulated by varying pellet concentrations, with low productivity treatments receiving $0.05 \mathrm{~g} \mathrm{~L}^{-1}$ and high productivity treatments receiving $0.95 \mathrm{~g} \mathrm{~L}^{-1}$. Pellet manipulations resulted in order of magnitude increases in bacteria and protist abundances indicating that the treatments were successful in enhancing productivity. All materials were autoclave sterilized before use.

Sterilized medium was first inoculated with three edible species of bacteria (Serratia marcescens, Bacillus cereus, and Bacillus subtilis). The protist stock cultures contained a diverse assemblage of bacteria that could accompany the protists when added to the experimental bottles. To ensure that all microcosms received the same initial bacteria community, a pooled bacterial inoculum was created by taking $5 \mathrm{~mL}$ water samples from the protist stock cultures and filtering the samples through a sterile $1.2 \mu \mathrm{m}$ filter to remove protists. The filtrate was then added to the experimental media. Bacteria were allowed to grow for one week at which time each experimental bottle received $200 \mathrm{~mL}$ of inoculated medium of appropriate pellet concentration, and protists 
were added to their appropriate treatments (100 individuals of each species). Hence, total protist densities differed between monocultures and polycultures at the start of the experiment. However, as initial densities were low and community dynamics were allowed to play out over an extended period of time (Figure 2), initial differences likely had minimal effects on observed responses. Beginning the second week of the experiment, I performed weekly replacements of $10 \%$ of the media from each replicate with sterile medium to replenish bacteria resources.

Density-independent mortality treatments were initiated 10 days following protist additions and continued until the termination of the experiment. Imposed mortality rates were in addition to mortality imposed by weekly nutrient replacements and consisted of $95 \%$ mortality every other day (high mortality) and $0 \%$ mortality (low mortality). To impose mortality, bottles were first mixed, and then the appropriate percentage of volume was poured into separate holding bottles and sonicated for three minutes using a $20 \mathrm{~W}$ sonic dismembrator. This duration was found to be effective in killing all protists in subsamples but had minimal impact on the bacteria. Following sonication, medium was returned to the source bottle. To ensure that all bottles received similar mixing regimes, bottles from low mortality treatments were mixed, poured into holding bottles, and poured back into the source bottle. I performed weekly additions of all four protist species ( 20 individuals of each species, isolated from stock cultures) beginning on day 11 up to day 32 , to provide opportunity for all species to invade following imposition of mortality treatments.

Protist populations were sampled on day 7 and day 15 and then every 4 days up to day 55 (the final sample). This duration was long enough to encompass up to 189 generations of the bacterivore species which had maximal generation times of approximately 7-17 hours [29]. Bottles were sampled by first mixing the contents and removing $2 \mathrm{~mL}$. Protists were then counted in subsamples of this volume using a dissecting scope. To acquire biomass estimates, protist densities were multiplied by species-specific biomass constants obtained from laboratory records. On day 56, mortality was again imposed, and on day 57 bacterial communities were sampled then plated on LB nutrient agar following serial dilutions. I used colony counts and colony morphotypes (based on colony color, edge, and surface morphology) as indicators of bacterial density and diversity [34-37]. For high productivity treatments, $10^{-3}, 10^{-4}$, and $10^{-5}$ dilutions were used; $10^{-2}, 10^{-3}$, and $10^{-4}$ dilutions were used for low productivity treatments. This allowed accurate enumeration of total colony density as well as detection of rare colony types.

2.1. Statistical Analysis. Analyses were restricted to the final six sample dates of the experiment, corresponding to the period after which protist additions were terminated. One high disturbance, low productivity polyculture replicate was lost due to methodological error and has been removed from all analyses. P. caudatum went extinct in all high disturbance, low productivity monoculture replicates. Loxocephalus went extinct in all low productivity, no disturbance monoculture replicates, and all high disturbance monoculture replicates, regardless of productivity level. Because inclusion of these treatments in monoculture means may have biased my results towards detecting diversity effects, I removed them from all analyses. Bacterial colony diversity was calculated using the Shannon-Wiener diversity index. Treatment effects (main effects and interactions) on bacterial diversity and density were analyzed using ANOVA. Permutational MANOVA was used to analyze treatment effects (main effects and interactions) on bacteria morphotype composition using BrayCurtis dissimilarities and 10000 permutations. Effects on composition were visualized using nonmetric multidimensional scaling (NMDS) based on the Bray-Curtis distances. Total bacterivore biomass in monocultures and polycultures was averaged over the last six sample dates and analyzed using ANOVA to test for main effects and interactions of diversity, productivity, and disturbance.

Significant diversity effects were detected only for bacteria responses (see Section 3). Numerical methods for partitioning diversity effects into complementarity and sampling effects are only applicable for response variables in which each species' contribution to the variable may be quantified in both mono- and polyculture $[21,38]$ or for response variables in which species contribute additively to the response [39]. Thus, this method could not be used for my bacteria results. As an alternative, I quantified overyielding using the $D_{\max }$ index, defined as the difference between the value of the response variable in polyculture and the maximal value among monocultures, divided by the maximal value among monocultures [38]. Separate $D_{\max }$ values were calculated for each polyculture replicate using the mean maximal value among bacterivore monocultures. As I was primarily interested in detecting complementarity effects among consumers in polyculture (versus sampling effects), I calculated $D_{\max }$ values using monocultures for only those consumer species that actually persisted in polyculture for the given treatment (results were similar when using all monocultures). In the case of bacterial response variables where consumer diversity was hypothesized to decrease both diversity and density, $D_{\max }$ was calculated using the mean minimal value among monocultures. Productivity and disturbance effects on $D_{\max }$ were then analyzed using ANOVA. All statistics were performed in $\mathrm{R}$ version 2.15 [40]. Because replication was unequal among treatments, composite ANOVA results based on type I sums of squares were constructed as described in [41]; model simplification and removal of higher order terms were performed as described in [42]. Post hoc comparisons were performed using the max $t$-tests which are robust to nonnormal data and unequal sample sizes [43]. To attain homogeneity of variances and meet assumptions of normality, bacteria density and bacterivore biomass measures were $\log _{10}$ transformed. $\mathrm{R}$ code for running the max $t$-tests can be found in [43]. Permutational MANOVA and NMDS were conducted using the vegan package for R [44].

\section{Results}

3.1. Consumer Responses. Block effects were not detected and have been removed from all analyses. Disturbance had 


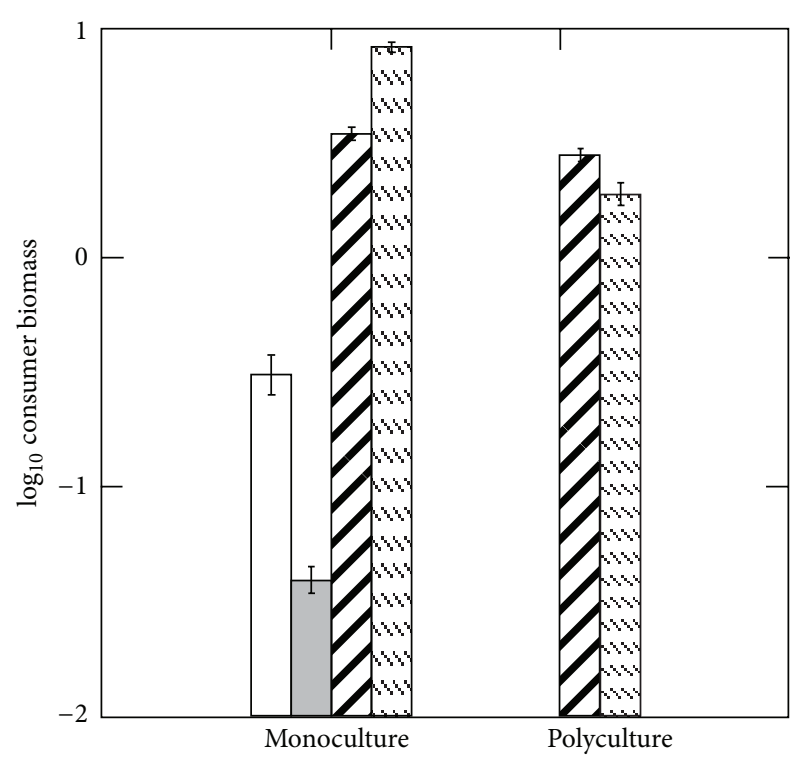

(a)

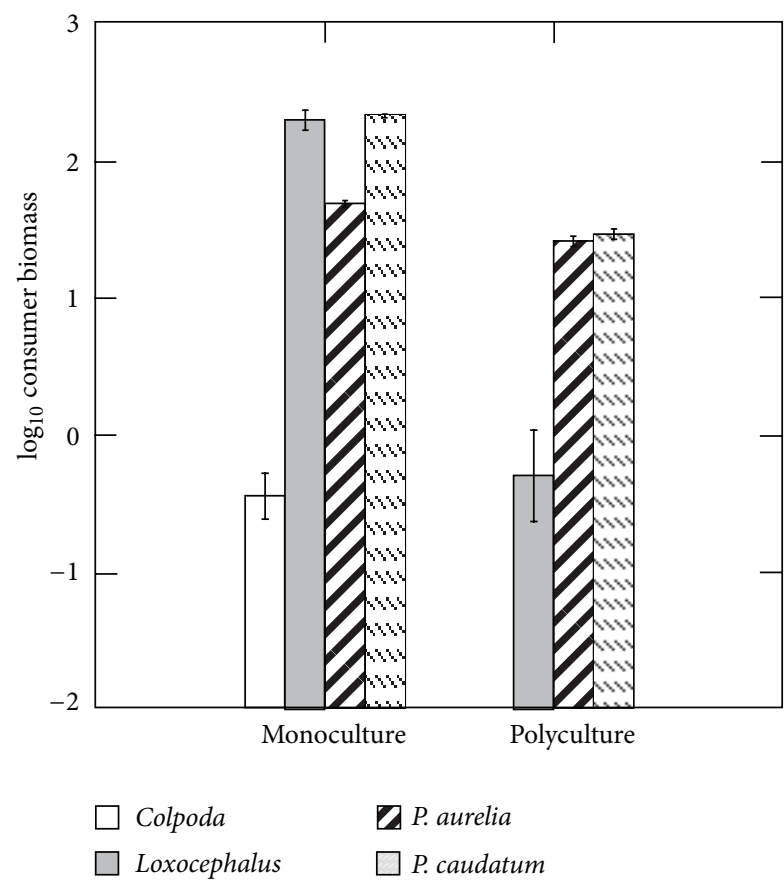

(c)

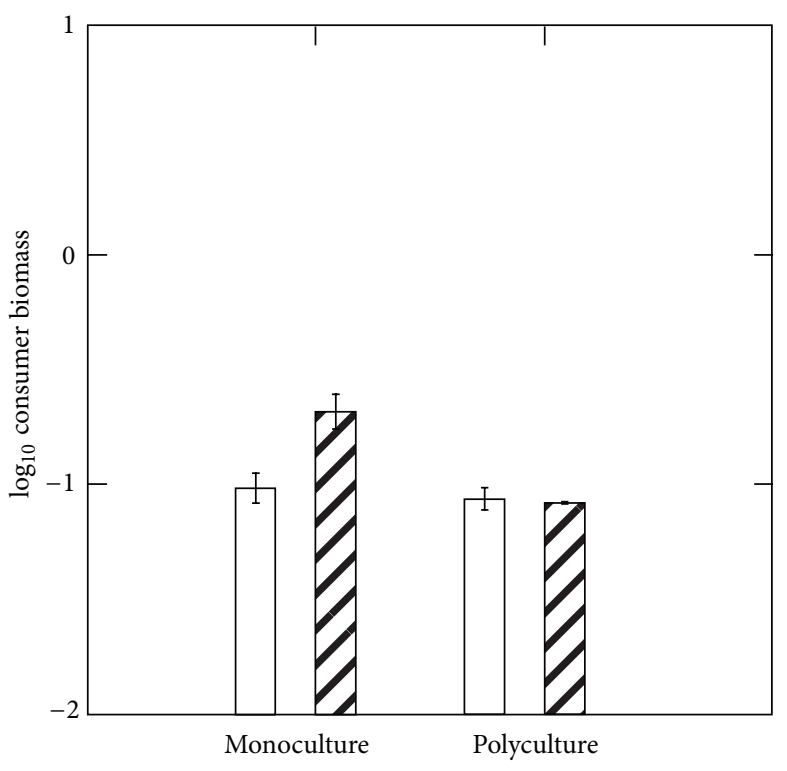

(b)

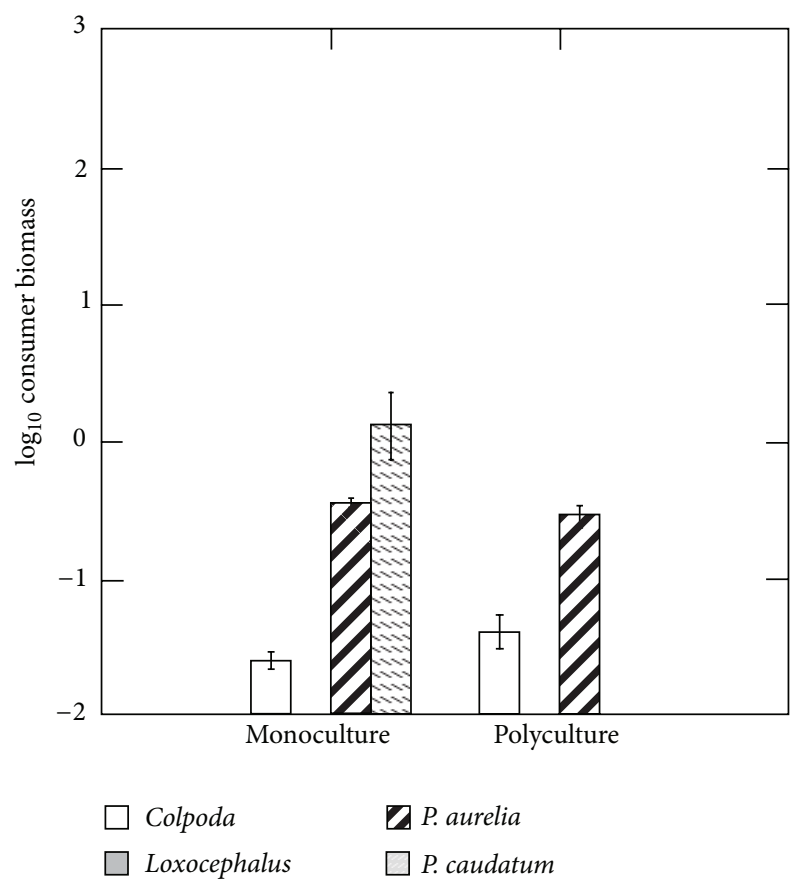

(d)

FIGURE 1: Effects of disturbance, productivity, and consumer diversity on the biomass of each consumer species averaged over the last six sample dates of the experiment (means \pm SE). Results are shown for consumers in monoculture or polyculture at (a) low productivity and low disturbance, (b) low productivity and high disturbance, (c) high productivity and low disturbance, or (d) high productivity and high disturbance. Original units in $\mu \mathrm{g} / \mathrm{mL}$.

strong effects on consumer species composition and relative abundance. Detailed statistical analyses and discussion of competitive dynamics and outcomes may be found in [29]. Here I summarize the basic results, displaying time-averaged biomasses in monoculture and polyculture (Figure 1). First, at both low and high productivity, P. aurelia and P. caudatum coexisted and dominated in polycultures at low disturbance
(Figures 1(a) and 1(b)). In contrast, at low productivity and in the high disturbance treatment, Colpoda was able to invade and dominate in polycultures, driving $P$. aurelia to low biomass levels (Figure 1(a)). A similar but weaker effect of disturbance was seen in high productivity treatments; Colpoda was able to invade in the high disturbance treatment, attained biomass levels comparable to $P$. aurelia, and 


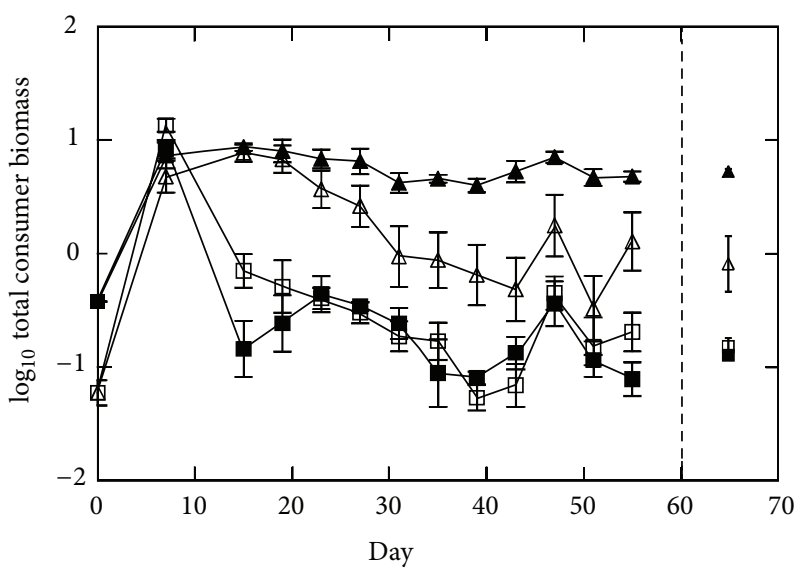

$\triangle$ Monoculture, low disturbance

$\Delta$ Polyculture, low disturbance

$\square$ Monoculture, high disturbance

Polyculture, high disturbance

(a)

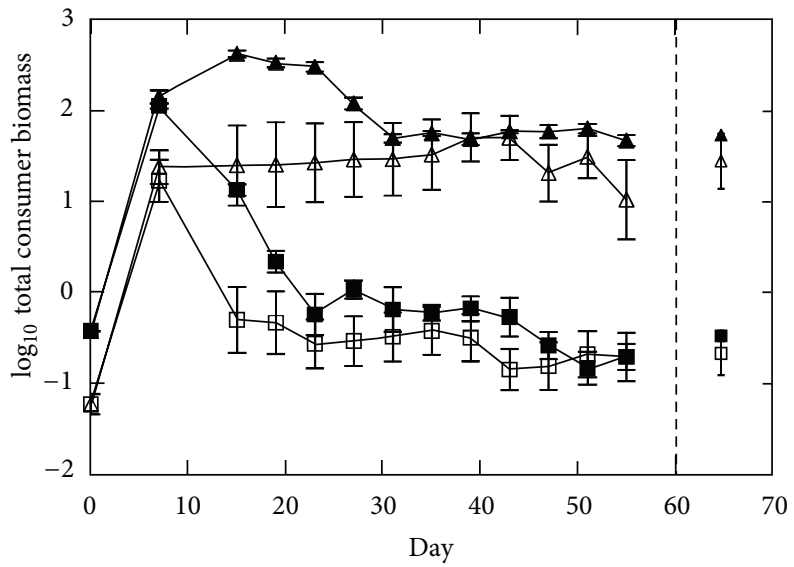

$\triangle$ Monoculture, low disturbance

$\Delta$ Polyculture, low disturbance

$\square$ Monoculture, high disturbance

Polyculture, high disturbance

(b)

FIGURE 2: Total consumer biomass in polycultures and averaged across monocultures (means \pm SE). Results are for low and high disturbance treatments at either (a) low productivity or (b) high productivity. Symbols to the right of the time series (separated by a vertical dashed line) are time-averages for the last six sample dates (means \pm SE). Original units in $\mu \mathrm{g} / \mathrm{mL}$.

drove $P$. caudatum below limits of detection (Figure 1(b)). P. caudatum was unable to persist in the high disturbance and low productivity treatment in both mono- and polycultures. Loxocephalus only persisted in monocultures and in the absence of disturbance.

No effects of consumer diversity on total consumer biomass were detected when averaging biomass over the last six sample dates $\left(F_{1,62}=2.05, P=0.16\right.$, ANOVA $)$. Moreover, no significant interactions between diversity and productivity/disturbance were detected (all $P>0.36$, ANOVA). Productivity and disturbance interactively affected time-averaged consumer biomass (Figure 2; $F_{1,62}=8.37$, $P<0.01$, ANOVA); productivity increased total consumer biomass in the absence of disturbance $(P<0.001$, max $t$-test $)$ but had not effect in the presence of disturbance $(P=0.49$, the max $t$-test).

3.2. Bacteria Responses. Seven bacterial morphotypes were identified based on colony morphology. Statistical comparisons of bacteria diversity and density between individual monocultures and polycultures are presented in [29]. Here I focus on comparisons between mean monoculture results and polycultures (i.e., diversity effects) and their interaction with productivity and disturbance. I also explore effects on bacteria morphotype composition.

Disturbance had a weak but statistically significant positive effect on bacteria density (Figure 3; $F_{1,62}=48.57$, $P=0.01$, ANOVA); no interactions with disturbance were detected (all $P>0.23$, ANOVA). Effects of consumer diversity on bacteria abundance varied with productivity level as indicated by a diversity $\times$ productivity interaction $\left(F_{1,62}=48.57, P<0.001\right.$, ANOVA $)$. At low productivity, density was reduced in polycultures relative to monocultures (Figure 3(a); $P<0.001$, max $t$-test) while no consumer diversity effects were detected in the high productivity treatments (Figure 3(b); $P=0.58$, max $t$-test). When examining $D_{\max }$ values, no disturbance effect or interaction between productivity and disturbance was detected $(P>0.17$, ANOVA). However, $D_{\max }$ was lower in low productivity treatments relative to high productivity treatments $\left(F_{1,12}=\right.$ 22.52, $P<0.001$, ANOVA; Table 1). At high productivity, $D_{\max }$ values did not differ from zero, regardless of disturbance level (Table 1). In contrast, significant negative values were detected at low productivity (Table 1).

Consumer diversity decreased bacteria diversity, but the magnitude of this effect varied with productivity level $\left(F_{1,62}=\right.$ $6.48, P=0.01$, diversity $\times$ productivity effect, ANOVA). At low productivity, no effects of consumer diversity were detected (Figure 4(a); $P=0.59$, max $t$-test). In contrast, at high productivity levels, bacteria diversity was significantly lower in consumer polycultures relative to monocultures (Figure 4(b); $P<0.001, \max t$-test). Disturbance also increased bacterial diversity (Figure $4 ; F_{1,62}=9.13, P=$ 0.004 , ANOVA). Disturbance appeared to interact with consumer diversity, having a stronger positive effect on bacterial diversity in the polyculture treatment (Figure 4). However, this effect was not significant at the $P<0.05$ level $(P=$ 0.09 , disturbance $\times$ diversity effect, ANOVA). No interactions between disturbance and productivity or between diversity, productivity, and disturbance were detected $(P>0.46$, ANOVA). Negative $D_{\max }$ values for bacterial diversity were uncovered for all treatments except for the low productivity and high disturbance treatment (Table 1). Accordingly, a significant interaction between disturbance and productivity 


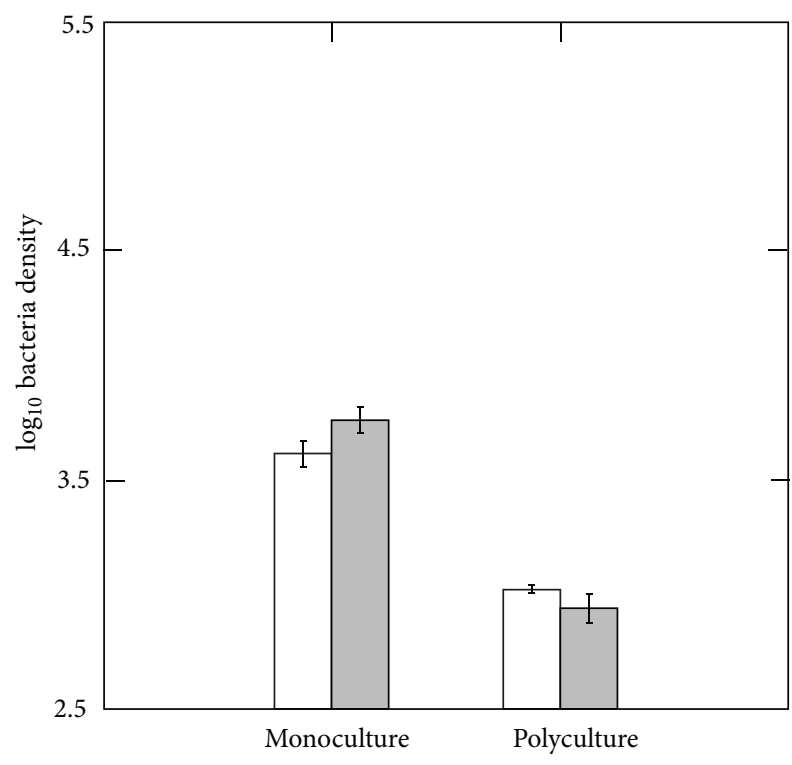

Low disturbance

High disturbance

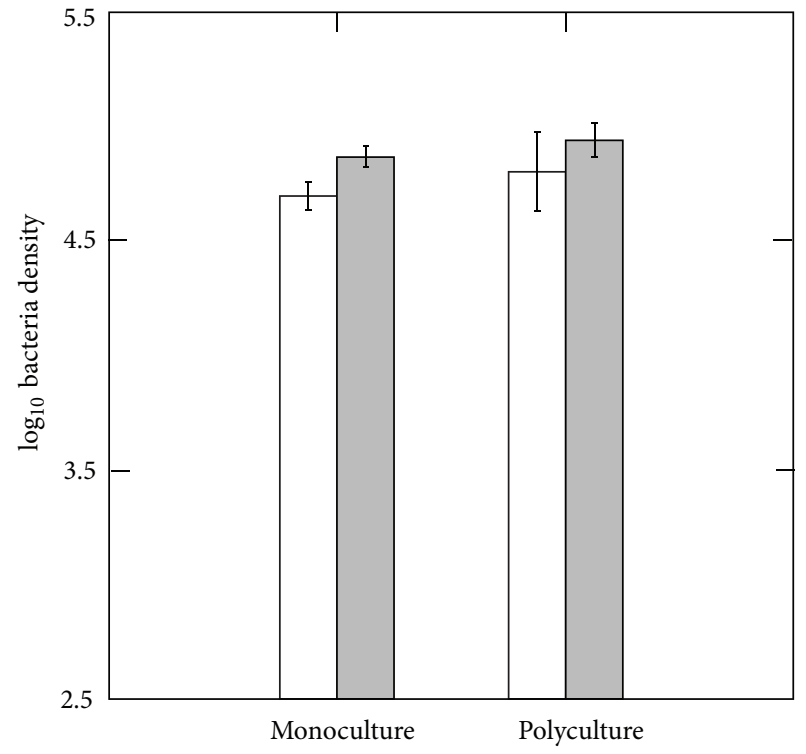

Low disturbance

High disturbance

(a)

(b)

Figure 3: Effects of disturbance and consumer diversity (mean monoculture versus polyculture) on total bacteria density for (a) low productivity treatments and (b) high productivity treatments. Shown are means $( \pm \mathrm{SE})$. Original units in individuals $/ \mathrm{mL}$.

TABLE 1: Mean $D_{\max }$ and 95\% confidence intervals for each productivity/disturbance treatment combination.

\begin{tabular}{lcc}
\hline Treatment & $D_{\max }$ (bacterial density) & $D_{\max }$ (bacterial diversity) \\
\hline Low productivity-low disturbance & $-0.784 \pm 0.022$ & $-0.709 \pm 0.551$ \\
Low productivity-high disturbance & $-0.845 \pm 0.070$ & $0.115 \pm 0.218$ \\
High productivity-low disturbance & $1.619 \pm 2.251$ & $-0.768 \pm 0.401$ \\
High productivity-high disturbance & $0.560 \pm 0.674$ & $-0.504 \pm 0.126$ \\
\hline
\end{tabular}

was detected when analyzing $D_{\max }$ using $\operatorname{ANOVA}\left(F_{1,11}=\right.$ 5.43, $P=0.04)$. $D_{\max }$ in the low productivity and high disturbance treatment was significantly greater than the three other treatment combinations (all $P<0.01$, $\max t$-test); no differences were detected among the three remaining treatment combinations (all $P>0.33$, max $t$-test).

Permutational MANOVA revealed a significant interaction between consumer diversity and productivity on bacteria morphotype composition $\left(F_{1,61}=9.13, P<0.0001\right)$. This effect was apparent when examining NMDS results of bacteria communities in all treatments (Figure 5). Diversity effects (closed versus open symbols) were stronger in high productivity treatments (red symbols, Figure 5) compared to low productivity treatments (black symbols, Figure 5). Consumer diversity effects on bacteria composition did not vary with disturbance nor was a three-way interaction between diversity, disturbance, and productivity detected (all $P>0.38$ ). Figure 6 displays mean abundances of each bacteria colony morphotype in polyculture and monocultures. For the following, I focused on comparisons between polycultures and the monocultures of only those species that persisted in polyculture (those marked with an asterisk in
Figure 6). At low productivity, densities of the dominant morphotypes ( 1 and 2 ) were lower in polycultures compared to monocultures (Figures 6(a) and 6(b); all $P<0.05$, the Bonferroni adjusted $t$-tests). At high productivity and in low disturbance treatments (Figure 6(c)), bacterivores in polyculture were able to suppress morphotype 2 densities below levels in monocultures (Figure 6(c); all $P<0.051$, Bonferroni adjusted $t$-tests); no differences were detected for the dominant morphotype $1(P>0.05)$. However, morphotypes 3,4 , and 6 were completely excluded in polycultures of this treatment (Figure 6(c)). At high productivity and high disturbance, no significant differences in densities were detected for morphotypes 1-4 when comparing polycultures and monocultures (Figure 6(d); all $P>0.05$, Bonferroni adjusted $t$-tests). However, morphotypes 5 and 6 , which were present in both Colpoda and P. aurelia monocultures, were excluded in polyculture (Figure 6(d)).

\section{Discussion}

Consistent with general predictions, consumers in polyculture reduced the abundance of bacterial prey when compared 


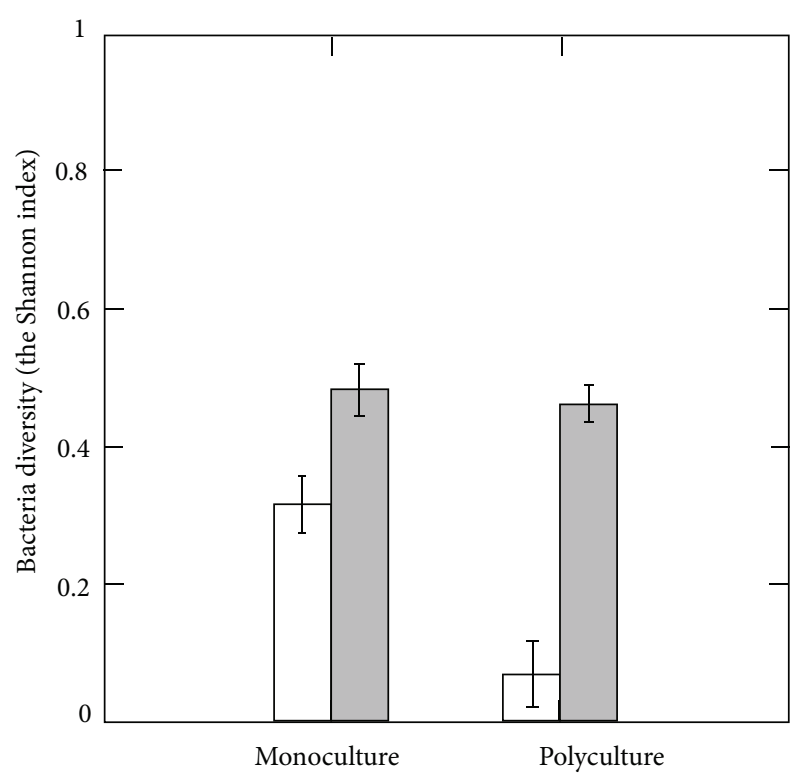

Low disturbance

High disturbance

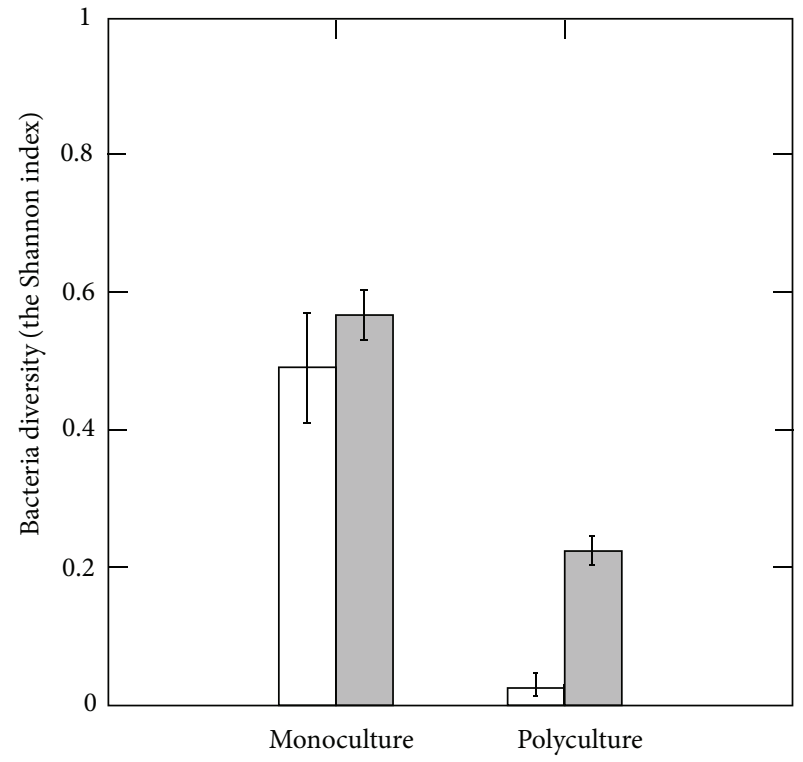

Low disturbance

High disturbance

(a)

(b)

FIGURE 4: Effects of disturbance and consumer diversity (mean monoculture versus polyculture) on bacteria morphotype diversity (the Shannon index) for (a) low productivity treatments and (b) high productivity treatments. Shown are means $( \pm \mathrm{SE})$.

to average monoculture levels. However, this effect was strongly dependent on productivity level with significant effects emerging only under low productivity conditions. One possible explanation is that bacterial composition shifted to taxa or forms that were more resistant to predation by bacterivores. Theoretical and empirical studies have shown that prey assemblages can exhibit shifts in abundance towards less edible prey when exposed to the combined action of predation and enhanced productivity, reducing the negative impacts of predators on total prey abundance $[1,6,9,10$, 23-25]. In the present study, reduced effects of consumers on bacterial abundance in polycultures were not due to a simple increase in abundance of all bacterial colony types under high productivity conditions. Rather, increases in total bacterial density in polycultures were due primarily to the compensatory responses of two bacteria colony morphotypes which increased in absolute and relative abundance under high productivity conditions. Thus, the level of enrichment and potential productivity of a system may play a pivotal role in determining the degree of compensation expressed by prey and the resultant strength of consumer diversity effects on total prey abundance. This may also explain why past consumer diversity studies have produced inconsistent results, with some finding strong diversity effects [17] and others weak effects due to compensatory responses among prey $[45,46]$.

Whereas increases in a minority of bacteria morphotypes allowed total bacterial density to increase in high productivity polycultures, this response was accompanied by the reduction or exclusion of several colony types. Consequently, bacterial diversity declined with increasing consumer diversity at high productivity. As explicated above, consumers can facilitate shifts in the composition of prey towards less edible forms via apparent competition at high productivity, reducing consumer control of total prey abundance. However, enhanced apparent competition with increasing productivity can also cause the reduction and exclusion of some prey species, increasing consumer control of prey diversity $[9,24]$. A potential source of concern is that bacterial diversity and density were measured using plating techniques. While plating is admittedly an inferior measure of bacterial density and diversity, studies comparing results from plating with direct density counts and genetic measures of bacterial diversity have shown that plating can effectively capture relative differences among experimental treatments [34-36]. Thus, my plate estimates may be viewed as proxy measures of bacterial density and diversity.

Diversity effects on emergent ecosystem properties are commonly thought to arise through two broad classes of processes: niche complementarity among species or sampling effects. In the latter, increased diversity increases the probability of inclusion of species that have inordinately strong effects on the focal ecosystem property in both monoculture and polyculture. Complementarity arises when species exhibit niche partitioning or facilitation and are thus able to more greatly impact an ecosystem property when in polyculture compared to any single species' monoculture. 


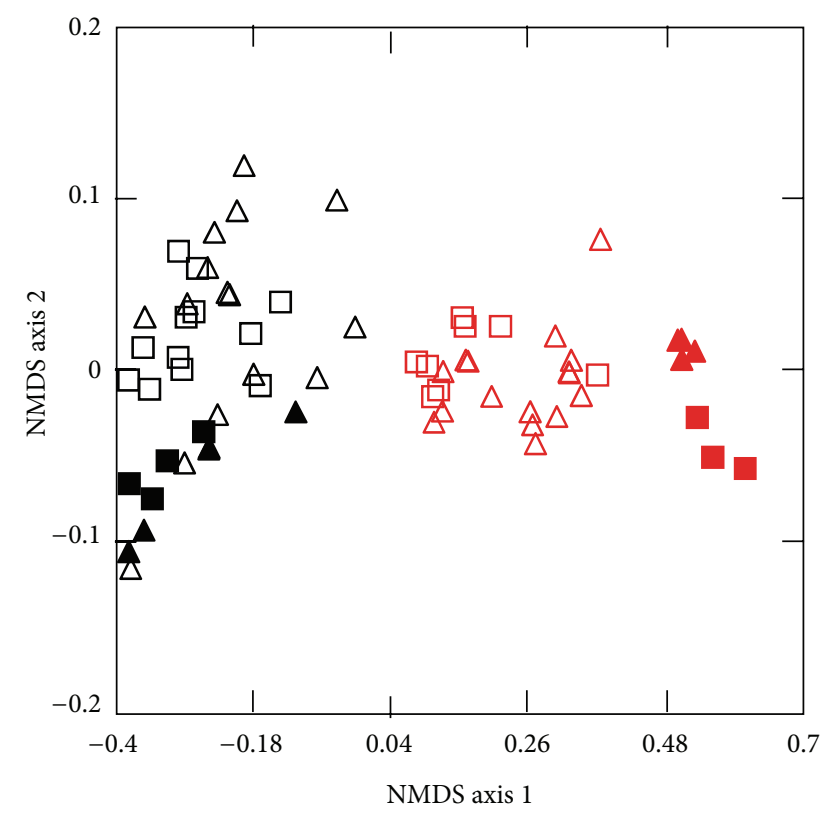

$\triangle$ Monoculture, low disturbance, low productivity

A Polyculture, low disturbance, low productivity

$\square$ Monoculture, high disturbance, low productivity

Polyculture, high disturbance, low productivity

$\triangle$ Monoculture, low disturbance, high productivity

A Polyculture, low disturbance, high productivity

$\square$ Monoculture, high disturbance, high productivity

Polyculture, high disturbance, high productivity

FIGURE 5: First two axes of the nonmetric multidimensional scaling analysis of bacteria morphotype composition. The analysis was performed using the Bray-Curtis dissimilarities of morphotype densities. Shown are results for all replicates of all treatment combinations. Squares correspond to high disturbance treatments and triangles correspond to low disturbance. Open symbols correspond to consumer monocultures and closed symbols correspond to consumer polycultures. Black symbols are low productivity treatments and red symbols are high productivity treatments.

Although I could not use standard mathematical techniques to partition sampling and complementarity effects on bacterial responses $[21,39], D_{\max }$ values indicated that complementarity among consumers was of greater importance than sampling effects. When examining bacterial density, significant negative $D_{\max }$ values were detected for all low productivity treatments. Thus, consumers in polyculture were able to reduce bacterial densities below the lowest mean diversity level among monocultures by up to $84 \%$ (Table 1 ). Similar results were obtained for bacterial diversity; for those treatments in which significant consumer diversity effects were detected, significant negative $D_{\max }$ values were uncovered. Bacterial colony responses also indicated that complementarity in resource usage drove observed patterns. For instance, in low productivity treatments, consumers in polycultures were able to suppress densities of the dominant colony types to levels significantly lower than those found in monocultures. Similar patterns held true for consumer effects on bacterial diversity in the high productivity treatments. Several bacterial colony types present in monocultures were driven below the limits of detection in polyculture. This is evidence that consumer diversity effects on bacterial prey were largely mediated by complementarity in resource usage among consumers rather than selection for a single consumer species of strong influence.

Unlike productivity, disturbance played a much weaker role in mediating consumer diversity effects. Disturbance did, however, exert strong main effects on consumers. As expected, total bacterivore abundance was greatly reduced under high mortality levels. Paradoxically, this did not translate into a strong positive indirect effect on total bacterial abundance. Examination of bacterial controls run concurrently with the present experiment indicated that disturbance imposed by sonication did not directly decrease bacterial densities [29]. One possible explanation is that top-down pressure combined with nutrient recycling by bacterivores permitted high population turnover of bacterial prey in low disturbance treatments weakening the contrast between low and high disturbance levels; similar effects have been proposed for terrestrial plant-herbivore systems $[47,48]$. Despite generally weak effects on bacterial density, disturbance significantly increased bacterial diversity in both mono- and polycultures. As shown by [28], disturbance in the form of density-independent mortality imposed on consumers can weaken apparent competition effects on prey assemblages, indirectly enhancing prey diversity. My results are consistent with this prediction but also suggest that density-independent mortality can interact with consumer diversity to influence prey diversity. Disturbance appeared to have a stronger positive effect on bacterial diversity in consumer polycultures compared to mean monoculture levels (Figure 4); this seemed to be especially true in low productivity treatments (Figure 4(a)). Consequently, consumer diversity effects on bacterial diversity were more strongly expressed in the absence of disturbance. $D_{\max }$ results also supported this contention (Table 1). Weaker consumer diversity effects at high disturbance may have been due to the compositional shift from $P$. aurelia and $P$. caudatum dominance at low disturbance to a community composed of $P$. aurelia and Colpoda at high disturbance. Though intriguing, this result should be viewed cautiously as the diversity $x$ disturbance interaction in ANOVA was only significant at the $P=0.09$ level.

In contrast to its effects on bacterial prey, diversity effects on consumer biomass yields were weak. This contradicts both theory and prior experiments which have found increases in total consumer biomass with increasing consumer diversity [17-20]. Furthermore, productivity and disturbance played little part in moderating consumer diversity effects on secondary production. As expected, productivity increased total consumer biomass but no interaction between productivity and consumer diversity was apparent. Similarly, disturbance strongly impacted consumer biomass, reducing yields by greater than two orders of magnitude in some cases. Yet, disturbance had little or no consistent influence on the 


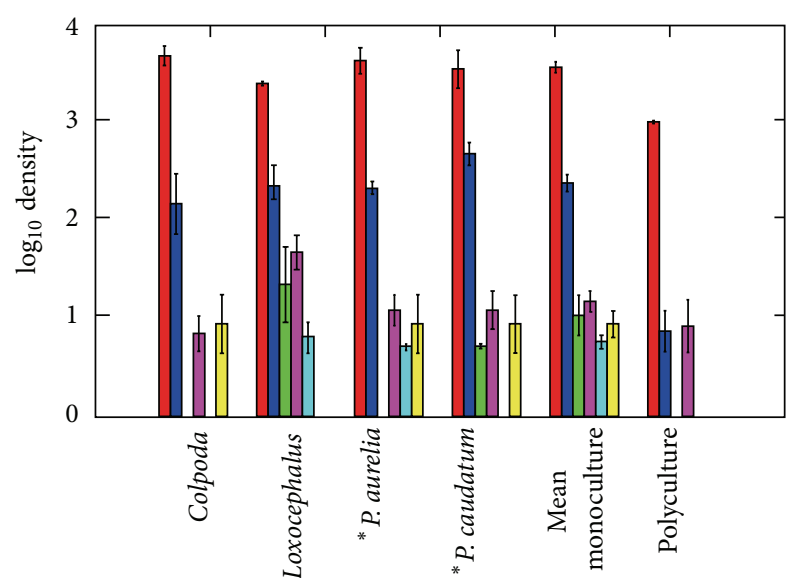

(a)

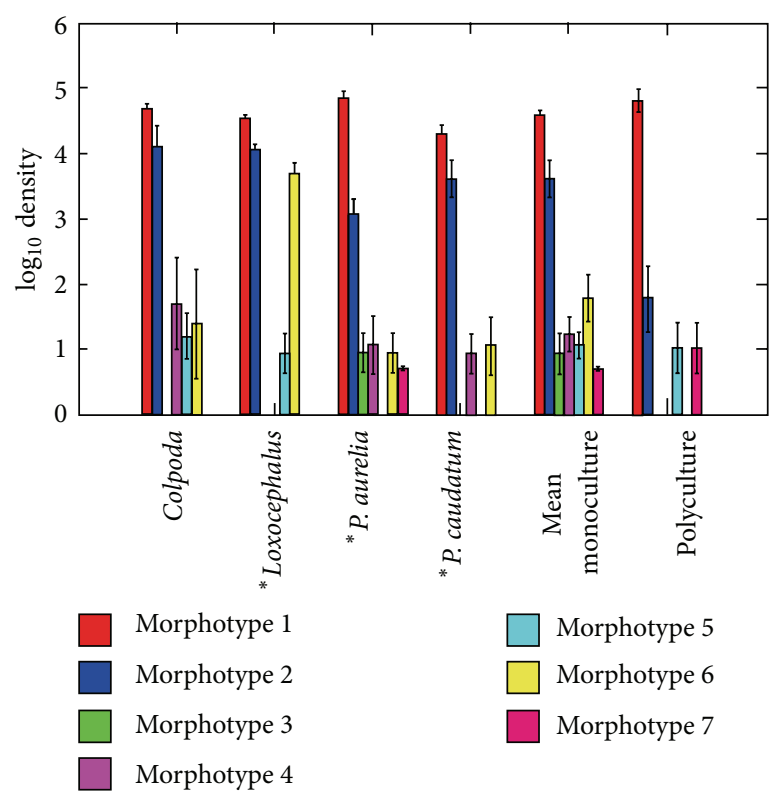

(c)

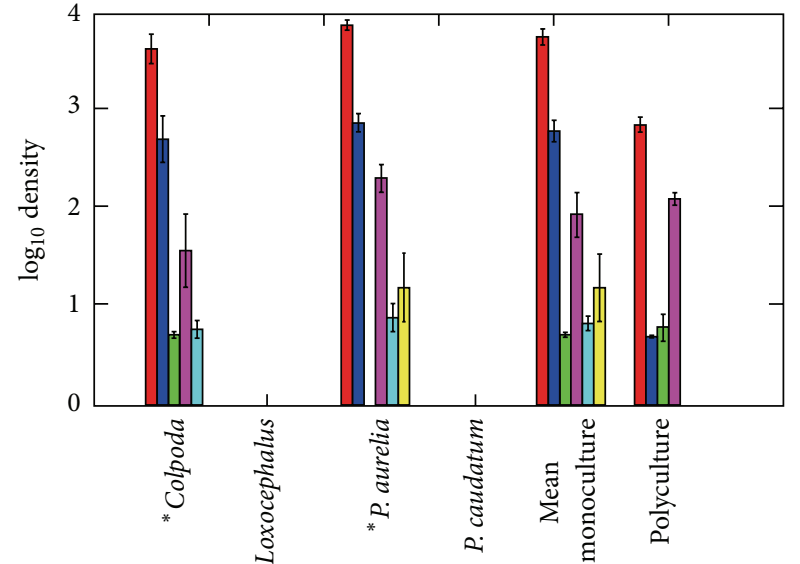

(b)

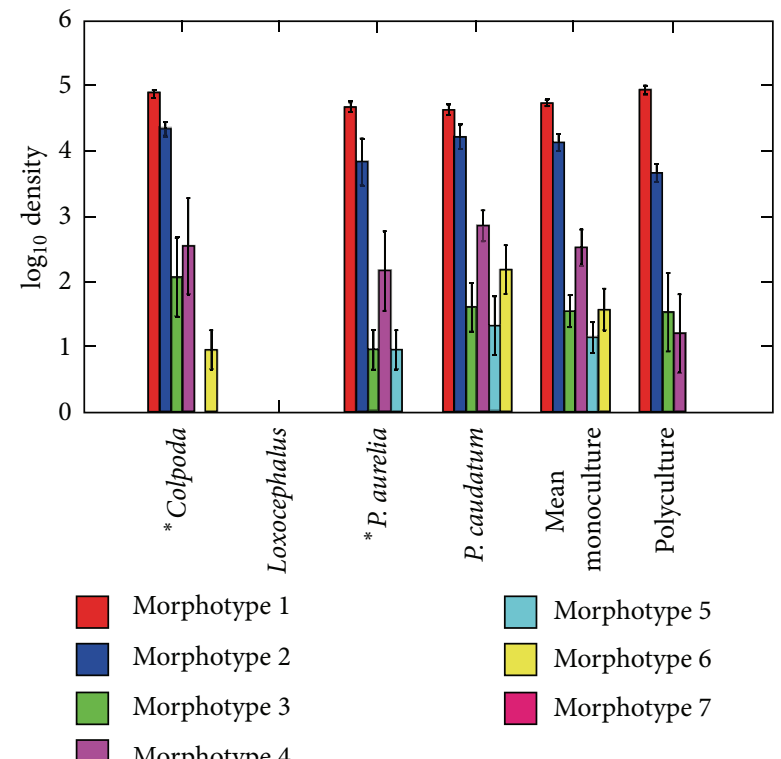

(d)

FIGURE 6: Mean densities of bacteria morphotypes (means \pm SE) in consumer monocultures, polycultures, and averaged across monocultures. Results are shown separately for (a) low productivity and low disturbance treatments, (b) low productivity and high disturbance treatments, (c) high productivity and low disturbance treatments, and (d) high productivity and high disturbance treatments. Monocultures marked by an asterisk $(*)$ are species that persisted in polyculture. Missing bars are for species that failed to persist in monocultures of the given treatment and have been removed from analyses. Original units in individuals $/ \mathrm{mL}$.

expression of diversity effects on consumer biomass. This is not unexpected given the effects disturbance had on consumer composition and diversity. Disturbance can mediate diversity effects on ecosystem properties by enhancing coexistence and realized species evenness in polycultures [32]. In the present experiment, disturbance strongly altered community composition but did not affect realized diversity; dominance by $P$. aurelia and $P$. caudatum at low disturbance was transformed into dominance by P. aurelia and Colpoda at high disturbance, regardless of productivity level. Moreover, disturbance did not increase evenness among bacterivores. When measuring evenness based on species' biomasses in polycultures using the modified Simpson dominance index (equation $E_{1 / D}$ in [49]), disturbance significantly reduced evenness averaged over the last six sample dates $(P<0.0001$, ANOVA). One potential criticism is that my high disturbance treatments may have been too severe, and increases in diversity and evenness may have been observed at lower mortality levels. However, additional mortality treatments imposed on polycultures at intermediate levels of $25 \%$ and $75 \%$ mortality failed to produce increases in diversity as well [29]. Given the evidence that disturbance can have strikingly variable outcomes on species diversity [50], the degree and manner in which it modifies diversity-ecosystem functioning relationships may vary greatly with environmental setting and the function in question. 
From early propositions of the importance of top-down effects to the present, the relative importance of consumers in the regulation of prey communities has generated intense debate $[1,3,51-53]$. Accordingly, numerous empirical and theoretical investigations have accumulated exploring factors that mediate the strength of top-down effects on prey assemblages. Despite this, experimental studies of the influence of consumer diversity on trophic-level biomass and prey diversity are a surprisingly recent phenomenon. The present examination adds to the growing body of research showing that consumer diversity can have important effects on emergent community properties. However, my study highlights the importance of environmental context as a potentially vital mediator of such effects; both productivity and, to a lesser degree, disturbance can alter the relationship between diversity and ecosystem properties.

\section{Acknowledgments}

Peter Morin, Members of the Morin lab, Jeremy Wojdak, and Emily Grman provided constructive comments on this project and paper. This research was supported by an NSF Microbial Postdoctoral Fellowship to the author.

\section{References}

[1] M. A. Leibold, J. M. Chase, J. B. Shurin, and A. L. Downing, "Species turnover and the regulation of trophic structure," Annual Review of Ecology and Systematics, vol. 28, pp. 467-494, 1997.

[2] G. G. Mittelbach, C. W. Osenberg, and M. A. Leibold, "Trophic relations and ontogenetic niche shifts in aquatic ecosystems," in Size-Structured Populations Ecology and Evolution, B. Ebenman and L. Persson, Eds., pp. 219-235, Springer, Berlin, Germany, 1988.

[3] G. A. Polis and D. R. Strong, "Food web complexity and community dynamics," The American Naturalist, vol. 147, no. 5, pp. 813-846, 1996.

[4] D. R. Strong, "Are trophic cascades all wet? Differentiation and donor-control in speciose ecosystems," Ecology, vol. 73, no. 3, pp. 747-754, 1992.

[5] J. M. Chase, "Are there real differences among aquatic and terrestrial food webs?" Trends in Ecology and Evolution, vol. 15, no. 10, pp. 408-412, 2000.

[6] J. M. Chase, M. A. Leibold, A. L. Downing, and J. B. Shurin, "The effects of productivity, herbivory, and plant species turnover in grassland food webs," Ecology, vol. 81, no. 9, pp. 2485-2497, 2000.

[7] H. Hillebrand, D. S. Gruner, E. T. Borer et al., "Consumer versus resource control of producer diversity depends on ecosystem type and producer community structure," Proceedings of the National Academy of Sciences of the United States of America, vol. 104, no. 26, pp. 10904-10909, 2007.

[8] J. B. Shurin, E. T. Borer, E. W. Seabloom et al., "A crossecosystem comparison of the strength of trophic cascades," Ecology Letters, vol. 5, no. 6, pp. 785-791, 2002.

[9] M. A. Leibold, "A graphical model of keystone predators in food webs: trophic regulation of abundance, incidence, and diversity patterns in communities," The American Naturalist, vol. 147, no. 5, pp. 784-812, 1996.
[10] C. F. Steiner, "The effects of prey heterogeneity and consumer identity on the limitation of trophic-level biomass," Ecology, vol. 82, no. 9, pp. 2495-2506, 2001.

[11] C. F. Steiner, "Keystone predator effects and grazer control of planktonic primary production," Oikos, vol. 101, no. 3, pp. 569$577,2003$.

[12] L. Jiang and P. J. Morin, "Predator diet breadth influences the relative importance of bottom-up and top-down control of prey biomass and diversity," The American Naturalist, vol. 165, no. 3, pp. 350-363, 2005.

[13] B. J. M. Bohannan and R. E. Lenski, "Effect of prey heterogeneity on the response of a model food chain to resource enrichment," The American Naturalist, vol. 153, no. 1, pp. 73-82, 1999.

[14] S. Naeem and S. B. Li, "Consumer species richness and autotrophic biomass," Ecology, vol. 79, no. 8, pp. 2603-2615, 1998.

[15] R. D. Holt and M. Loreau, "Biodiversity and ecosystem functioning: the role of trophic interactions and the importance of system openness," in Biodiversity and Ecosystem Function, A. Kinzig and S. Pacala, Eds., pp. 246-262, Princeton University Press, Princeton, NJ, USA, 2001.

[16] J. E. Duffy, "Biodiversity and ecosystem function: the consumer connection," Oikos, vol. 99, no. 2, pp. 201-219, 2002.

[17] J. E. Duffy, J. P. Richardson, and E. A. Canuel, "Grazer diversity effects on ecosystem functioning in seagrass beds," Ecology Letters, vol. 6, no. 7, pp. 637-645, 2003.

[18] A. R. Ives, B. J. Cardinale, and W. E. Snyder, "A synthesis of subdisciplines: predator-prey interactions, and biodiversity and ecosystem functioning," Ecology Letters, vol. 8, no. 7, pp. 102-116, 2005.

[19] J. M. Wojdak, "Relative strength of top-down, bottom-up, and consumer species richness effects on pond ecosystems," Ecological Monographs, vol. 75, no. 4, pp. 489-504, 2005.

[20] B. J. Cardinale, D. S. Srivastava, J. E. Duffy et al., "Effects of biodiversity on the functioning of trophic groups and ecosystems," Nature, vol. 443, no. 7114, pp. 989-992, 2006.

[21] M. Loreau and A. Hector, "Partitioning selection and complementarity in biodiversity experiments," Nature, vol. 412, no. 6842, pp. 72-76, 2001.

[22] J. Byrnes, J. J. Stachowicz, K. M. Hultgren, A. R. Hughes, S. V. Olyarnik, and C. S. Thornber, "Predator diversity strengthens trophic cascades in kelp forests by modifying herbivore behaviour," Ecology Letters, vol. 9, no. 1, pp. 61-71, 2006.

[23] J. P. Grover, "Competition, herbivory, and enrichment: nutrientbased models for edible and inedible plants," The American Naturalist, vol. 145, no. 5, pp. 746-774, 1995.

[24] R. D. Holt, J. Grover, and D. Tilman, "Simple rules for interspecific dominance in systems with exploitative and apparent competition," The American Naturalist, vol. 144, no. 5, pp. 741771, 1994.

[25] B. J. M. Bohannan and R. E. Lenski, “The relative importance of competition and predation varies with productivity in a model community," The American Naturalist, vol. 156, no. 4, pp. 329$340,2000$.

[26] C. F. Steiner, C. A. Klausmeier, and E. Litchman, "Transient dynamics and the destabilizing effects of prey heterogeneity," Ecology, vol. 93, no. 3, pp. 632-644, 2012.

[27] W. P. Sousa, “The role of disturbance in natural communities," Annual Review of Ecology and Systematics, vol. 15, pp. 353-391, 1984. 
[28] P. A. Abrams, "The effect of density-independent mortality on the coexistence of exploitative competitors for renewing resources," The American Naturalist, vol. 158, no. 5, pp. 459-470, 2001.

[29] C. F. Steiner, "Impacts of density-independent mortality and productivity on the strength and outcome of competition," Ecology, vol. 86, no. 3, pp. 727-739, 2005.

[30] J. T. Wootton, "Effects of disturbance on species diversity: a multitrophic perspective," The American Naturalist, vol. 152, no. 6, pp. 803-825, 2000.

[31] C. Violle, Z. Pu, and L. Jiang, "Experimental demonstration of the importance of competition under disturbance," Proceedings of the National Academy of Sciences of the United States of America, vol. 107, no. 29, pp. 12925-12929, 2010.

[32] B. J. Cardinale and M. A. Palmer, "Disturbance moderates biodiversity-ecosystem function relationships: experimental evidence from caddisflies in stream mesocosms," Ecology, vol. 83, no. 7, pp. 1915-1927, 2002.

[33] B. J. Cardinale, M. A. Palmer, A. R. Ives, and S. S. Brooks, "Diversity-productivity relationships in streams vary as a function of the natural disturbance regime," Ecology, vol. 86, no. 3, pp. 716-726, 2005.

[34] J. L. Garland, K. L. Cook, J. L. Adams, and L. Kerkhof, "Culturability as an indicator of succession in microbial communities," Microbial Ecology, vol. 42, no. 2, pp. 150-158, 2001.

[35] A. K. Müller, K. Westergaard, S. Christensen, and S. J. Sørensen, "The diversity and function of soil microbial communities exposed to different disturbances," Microbial Ecology, vol. 44, no. 1, pp. 49-58, 2002.

[36] L. D. Rasmussen and S. J. Sørensen, "Effects of mercury contamination on the culturable heterotrophic, functional and genetic diversity of the bacterial community in soil," FEMS Microbiology Ecology, vol. 36, no. 1, pp. 1-9, 2001.

[37] J. A. Krumins, Z. T. Long, C. F. Steiner, and P. J. Morin, "Indirect effects of food web diversity and productivity on bacterial community function and composition," Functional Ecology, vol. 20, no. 3, pp. 514-521, 2006.

[38] O. L. Petchey, "Integrating methods that investigate how complementarity influences ecosystem functioning," Oikos, vol. 101, no. 2, pp. 323-330, 2003.

[39] J. W. Fox, "Using the price equation to partition the effects of biodiversity loss on ecosystem function," Ecology, vol. 87, no. 11, pp. 2687-2696, 2006.

[40] R Development Core Team, $R$ : A Language and Environment for Statistical Computing, R Foundation for Statistical Computing, Vienna, Austria, 2011, http://www.R-project.org/.

[41] A. Hector, S. von Felten, and B. Schmid, "Analysis of variance with unbalanced data: an update for ecology \& evolution," Journal of Animal Ecology, vol. 79, no. 2, pp. 308-316, 2010.

[42] M. J. Crawley, The R Book, John Wiley \& Sons, West Sussex, UK, 2007.

[43] E. Herberich, J. Sikorski, and T. Hothorn, "A robust procedure for comparing multiple means under heteroscedasticity in unbalanced designs," PloS ONE, vol. 5, no. 3, Article ID e9788, 2010.

[44] J. Oksanen, F. G. Blanchet, R. Kindt, P. Legendre, R. B. O'Hara et al., "Vegan: Community Ecology Package," R package version 1. 17-4, 2010, http://CRAN.R-project.org/package=vegan/.

[45] J. Norberg, "Resource-niche complementarity and autotrophic compensation determines ecosystem-level responses to increased cladoceran species richness," Oecologia, vol. 122, no. 2, pp. 264-272, 2000.
[46] C. F. Steiner, T. L. Darcy-Hall, N. J. Dorn, E. A. Garcia, G. G. Mittelbach, and J. M. Wojdak, "The influence of consumer diversity and indirect facilitation on trophic level biomass and stability," Oikos, vol. 110, no. 3, pp. 556-566, 2005.

[47] C. de Mazancourt, M. Loreau, and L. Abbadie, "Grazing optimization and nutrient cycling: When do herbivores enhance plant production?" Ecology, vol. 79, no. 7, pp. 2242-2252, 1998.

[48] S. J. McNaughton, "Ecology of a grazing ecosystem: the Serengeti," Ecological Monographs, vol. 55, no. 3, pp. 259-294, 1985.

[49] B. Smith and J. B. Wilson, "A consumer's guide to evenness indices," Oikos, vol. 76, no. 1, pp. 70-82, 1996.

[50] R. L. Mackey and D. J. Currie, "The diversity-disturbance relationship: is it generally strong and peaked?" Ecology, vol. 82, no. 12, pp. 3479-3492, 2001.

[51] N. G. Hairston, F. E. Smith, and L. B. Slobodkin, "Community structure, population control, and competition," The American Naturalist, vol. 94, pp. 421-425, 1960.

[52] W. W. Murdoch, "Community structure, population control, and competition-a critique," The American Naturalist, vol. 100, pp. 219-226, 1966.

[53] A. Sih, P. Crowley, M. McPeek, J. Petranka, and K. Strohmeier, "Predation, competition, and prey communities: a review of field experiments," Annual Review of Ecology and Systematics, vol. 16, pp. 269-311, 1985. 

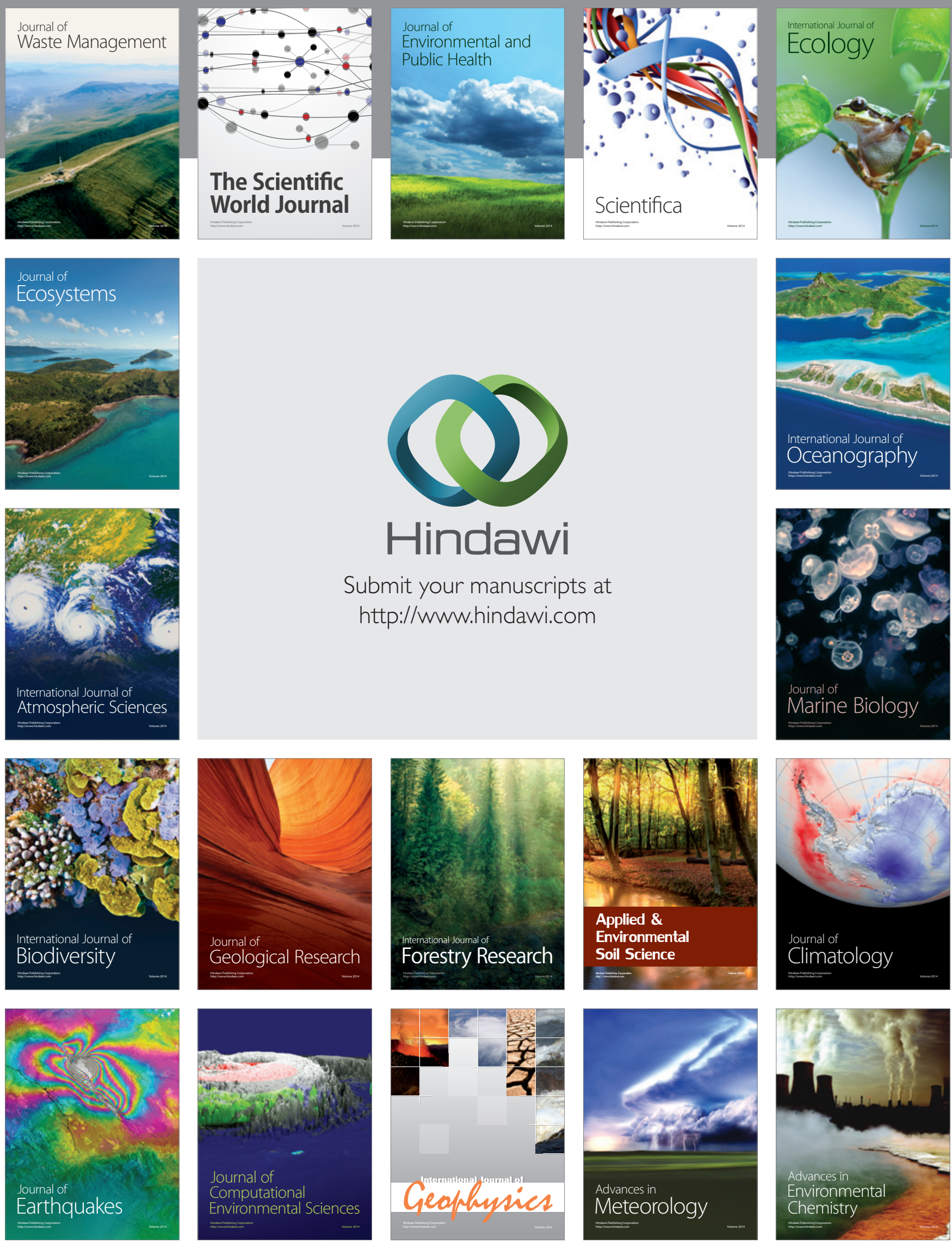